\title{
Study on the Protection and Development of Ancient City
}

\author{
Li Yan \\ Institute of art and design, Huanghe Science and Technology College, Zhengzhou, China, 450063 \\ ylhhkj@163.com
}

\begin{abstract}
Keywords: Historical and cultural city, Historical context, Protection, Development
Abstract. Chinese city urbanization process of rapid and large-scale city construction opportunity, the historical and cultural city also ushered in a period of accelerated development of good. We feel in the new city also inevitably have some regrets and regret: city to large-scale development, economy, modernization, erodes the history cultural heritage survival environment, many historic traditional culture is disappearing. At the same time, powerful modernization and internationalization, more make many historical ancient city in being completely replaced the position of history and traditional culture, living environment has be placed in jeopardy. In this from the old to the new, from the traditional to the modern transformation, the continuation of our country needs to historical context, don't want to be in the transformation process of modernization to abandon their own cultural heritage. This paper takes the historical and cultural city as the research object, and tries to explore a series for the historical and cultural characteristics of the ancient city, methods and thoughts of protection and continuation of the historical context of the city, in order to in the future city construction, cultural heritage is preserved.
\end{abstract}

\section{Introduction}

Historical and cultural city refers to the approval of the State Council and the provincial government, has a rich cultural heritage, many historical places of historic interest and scenic beauty, or is of important historical significance to commemorate the revolution, or a combination of the outstanding natural style of the city. Historical and cultural city on basis of nature, its type, can be divided into places of historic interest and scenic beauty, the history of the ancient city of Military Town, traffic, landscape, revolutionary memorial and comprehensive cultural city and other 6 categories.

In the world, new regionalism is the main development direction of building today, all countries are generally begin to confront the research and innovation of the regional architecture. This research focuses on the development and protection of traditional architecture culture, emphasizes the organic combination of traditional culture and modern architecture. The development of protective transformation is a favorable environment of the old city. City of accelerative transformation period, city and architecture into the renovation of the building, the traditional social and cultural back ground of rapidly changing city, structure, space layout and architectural style of great changes have taken place in the quality and quantity of resources, the protection of architectural culture in the history and natural resources has become one of the major problems of city development consider.

\section{Historical and Cultural City Protection and Construction of the Challenge}

With the rapid development of economy, the majority of city to city Chinese development drives the comprehensive construction well-off society, in this situation, the protection and construction of the historical and cultural city will face a new challenge.

With the city development as the leading economy drives the strategy, will inevitably lead to the contradiction between the protection of historical and cultural city and the development, produce conflict between the old and the ne w, modern and history. In the past 20 years, many of the city is in the name of modernization, city of big demolition Dajian, constantly, into a piece of the ancient streets and quaint houses demolished, the memory of the city in the reduction, the 
characteristic of the city disappear, historical and cultural city should not protect, in a hurry in the modernization process, pay a painful price. With the city accelerated, city population increase, follow close on succession of housing, employment, transportation, education, aging problem, bring enormous pressure to the old city area of the protection of the ancient city of their land, slightly careless, the site of the ancient city will lose one's beyond recognition. In the ecological, historical and cultural city in the long historical development period, has the natural ecological environment and its surrounding melting as a whole, it has a limited capacity of the environment and limited ecological stability ring, if more than the capacity of the enviro nment and destroyed the ecosystem stability ring will make the environment imbalance, a continuation of the ancient city the result of the historical context.

City development planning faced challenge. How to plan a city's development is a key city of development lies. Handle the relationship between the old city and the metro in the planning of the good, and is the key to the protection of the ancient city is located. Therefore, to solve the contradiction of city development and planning. Is the key to solve the city construction and the continuation of the context. Only the scientific planning, the protection of the ancient town of science into the above planning ideas, not only can the ancient relics protection and powerful, and can promote the development of the city.

Continuation of historical context and social and economic development of the contradictions, but also one of the important problems of historical culture of the ancient city protection and construction faces. The historical context in context basis by a city, a country, the historical legacy of culture essence and the historical origins of the aggregate. Can be said to be representing a city style, culture, history.

In many cases, people tend to give to the protection of historical context and pay attention to the immediate economic benefits, especially the so-called "image project" rising in recent years, many city "image", "square big heat", in order to open up the square and not borrow damage to historical sites, kill the historical sites of the social benefit and economic benefit an "image" benefit. Therefore, future oriented city in the planning, must make the future benefits in the first place, the viewpoint of sustainable development of city, the history and the present and future of organic unity together, if blindly value and interest and cut the city memory. Then the future benefits will not be rich.

In the reproduction of historical relics, keep the contradiction between existing style and the imitation relics sites. Cultural diversity and geographical features gradually decline and disappear, architectural culture and city culture appeared the trend phenomenon and crisis.

For a time, antique false wave of fanaticism, subsequently proved many place to build a palace garden not only most people fail, more complaints, and visitors to look the same everywhere "ancient" buildings are not interested, so, artificial landscape should return to rational development of the voice is up. There have been also built palace garden, antique fraud phenomenon in many city, its original intention is to recreate the ancient landscape, however lonely shadow only manmade landscape greatly hurt the historical context. Many historical view in the world, including the ancient city ruins, it is precisely because of its current situation, and enhance its cultural value. Therefore, in the new historical conditions, to maintain the existing contradiction between the remains of style and the imitation relics, select the most meaningful and valuable resource, reproducing the continuation of historical development of the context is the key.

The difficulty of protection and the development. There are two major historical and cultural city protection and development. On the one hand, to bring the city the process of modern economic development accelerated, modern urban people reknowing the spirit of traditional culture, the concept of value, life style to bring protection requirements; on the other hand, the traditional architecture and city space because of the backward municipal facilities can not adapt to the needs of modern life and brings forward the new problem. History and tradition is the spiritual pillar of a nation's history, the environment is part of human daily life environment, is the social presence of the past, with its rich historical heritage to life today to bring diversification. Therefore, as for traditional protection is not only to retain the material environment, should be reflected in the 
continuation of the social life of the bearing and, and can be incorporated into the modern economic and social development and demand.

\section{The Principle of Protection and Development}

The historical context of the city can preserved relatively intact, protection consciousness and measures of hand thanks to the local, on the other hand also shows that the region in the past period of time development is relatively backward. This will inevitably bring about the quality of housing aging, outdated infrastructure, the deterioration of environment problems of city living. If these problems can not be solved, not only affect the enthusiasm of residents protection, and will inevitably lead to suffocation and further destruction of historic district. In principle, we observe the following points:

The protection of the ancient city of culture, from the city to the overall development of the global and the city to do the protection and planning work, and not simply consider the protection of historical monuments and historical buildings.

To take into account the protection of historical and cultural heritage, social progress, economic development and the improvement of the living environment, the coordination of protection and development.

In full respect for the premise of historical environment, historical and cultural protection, reasonable development and utilization of some historical and cultural relics.

Study on the analysis of the history of the ancient city of characteristics, fully exploring and inheriting historical and cultural connotation, promoting the city's construction of spiritual civilization and material civilization.

The protection of repair, remediation and restoration of traditional Chinese medicine "the old before", "to keep the truth", the preservation of cultural relics and historic buildings should be "prolong life", rather than "renew one's youth".

\section{Method for the Protection of the Ancient City of Historical Culture}

Method of protection of cultural relics. Cultural relics is the basis of historical and cultural city, the protection work should pay attention not only to the ground visible artifacts, but also pay attention to buried in the underground cultural relics and sites: pay attention to both the ancient cultural relics, but also pay attention to the modern representative of the building and revolutionary memorial.

In the concrete protection method on the freezing preservation and reconstruction of the two measures.

Freezing preservation. Up protection will protect object wholly intact, allowing the necessary repair and reinforcement, but must be don't change the original premise, and repair and add part should be identified, namely, repair old as the old principle. Especially with high archaeological value and historical literature value of heritage buildings in the repair work, emphasizing the Historical Archaeology Research of its comprehensive, must respect the original data and conclusive archaeological evidence, there can be no guesswork.

Reconstruction. The history of some very important building due to various reasons have been destroyed, but they are crucial for local characteristics, plays a symbolic role, therefore, in the conditions allow reconstruction is necessary. But the reconstruction must be careful, because reconstruction must lose the historical authenticity, save the remnants of more value in most cases.

Protection method of historical area. 1976 "Nairobi proposal" with particular emphasis on the universal value of the historical section in the social aspect and practical aspect, and points out that they not only can be used as a witness of history, but also reflects the city's historical context. In the continuation of China's ancient city of historical context, has the extremely important practical significance to protect historical sites, because the traditional pattern and style protection, need to complete comprehensive protection of the ancient city after all have a few. For most city, the focus of several historical area preservation as a representative of the ancient city of which reflect the 
traditional pattern and style, displaying the city's development of historical continuity and cultural characteristics is feasible method. We present ways of protection of two types: "Museum" protection and "collage" protection.

Museum type protection. After the main refers to the sections of the building for the restoration and repair of old life together, will be saved, as an important facility for people to visit, study and tourism. American Willy James and Fort Williams the old site is using this way to protect, many other countries also have this city of Fort Williams, which is the most typical.

Collage type protection. This way is for the valuable ancient dwellings scattered or in the city, which can be relocated building can be in accordance with the environmental requirements of selecting concentrated in one place, to create a "historic" meeting, especially in the face of the transformation of the area and historic buildings in the city development process, and be engulfed the building boom that, rather than reconstructing. Such as seventy or eighty's Jiangxi Jingdezhen will be some difficult protection in villages scattered in the Ming Dynasty, residence, ancestral temple kilns focus moved to a site, planning into ancient porcelain workshop area, not only to facilitate the centralized protection, but also is convenient for centralized ornamental, but also solves many of the contradictions in the City construction.

Protection method of integral space environment of city. The overall protection of city space environment reflects the overall style and characteristics of the ancient city of the ancient city, is the key to distinguish ordinary city location. It must start from the city, and not a single starting from the city a few precious cultural relics or lot. Because even if delimit the scope of protection of cultural relics or lot, formulated the protection method, but the changes of the surrounding environment is not controlled, the overall characteristics of the style of the ancient city will lose.

\section{Summary}

Must adopt a holistic and comprehensive measures for the protection and control of the whole urban space environment: the original factors on urban space characteristics reflect traditional protection implementation on the one hand, to control and guide the new influence factors of urban style and features of the implementation on the other hand, so as to achieve the overall coordination of protection and development.

\section{References}

[1] Ming Zhi, several problems of small and medium-sized historical and cultural city protection planning and implementation of urban planning, 1987

[2] Qirong Li, urban planning and historical and cultural protection [M] Southeast University press, 2003

[3] Liangyong $\mathrm{Wu}$, the area of the building and the city: a living environment the concept of regional architecture research [M] Beijing: Tsinghua University press, 2010

[4] Ke Fang, in contemporary Beijing urban renewal [M] Beijing: Chinese Architecture Industry Press, 2000

[5] Binyi Liu, the modern landscape planning and design [M] Nanjing: Southeast University press, 1999

[6] Song Zhang, Historical city protection -- the introduction of cultural heritage and a holistic approach and historical environment protection [M] Shanghai science and Technology Press, 2010 